\title{
Impact of Augmented Reality on Vocabulary Acquisition and Retention
}

\author{
Megan Tyson \\ York College of Pennsylvania
}

\begin{abstract}
The present study investigated the impact teaching academic vocabulary through an augmented reality (AR) approach had on acquisition and retention as compared to using a more traditional flash card based approach. 29 high school students ranging from 9th to 11th grade followed the pattern of a 10 word vocabulary pre-test, being taught those words through respective alternating AR and traditional vocabulary methods, and post-tested one week from the date of teaching. At the end of the testing and teaching process, the unit scores were compared to find if any differences occurred. Analysis revealed that there is a significant difference between the two teaching methods. Participants scored better in the AR unit as compared to the traditional unit. Furthermore, participants also reported greater satisfaction with the AR method because it held their attention, gave them something to focus on, and was overall more engaging. Comparatively, participants found the traditional method not engaging, however, they were comfortable with the traditional method because it is what they are comfortable with in the classroom. Given the curiosity of using AR in the classroom, more research could be conducted to find patterns in participant performance across all academic content areas as well as other uses for AR in the classroom.
\end{abstract}

Keywords: Augmented Reality, Vocabulary, Academic Vocabulary, High School, Educational Technology, Multimedia Learning

Augmented reality (AR) is a tool that can make the impossible possible in the classroom. AR allows educators to create unique situations for their participants to make more authentic connections to their learning, which can allow for easier acquisition and longer retention. Unfortunately, a vast majority of educators do not understand the value of $A R$ and how simple it is to implement $A R$ in the classroom. Therefore, once educators have a solid understanding of the impact AR has on a student's acquisition and retention of new knowledge, educators will be more likely to implement this tool into their classrooms. This project connects to the Cognitive Theory of Multimedia as it explores the many ways in which students can acquire new knowledge through thought, the senses, and experience. The goal of this project is to determine the impact AR makes on students' acquisition of new knowledge and retention length. AR is one tool that could bridge the gap between traditional and technological methods that can open a new world for students to experience without ever leaving the physical classroom. 


\section{Literature Review}

Augmented reality is a tool that may not have been initially designed for the classroom, but like many real-world tools, these tools eventually find a place within the classroom setting for educators to continue preparing their students for their post-secondary lives. Today's students respond well to the instant gratification of a game-like learning setting that AR can offer. AR can take students to places that would not be possible due to uncontrollable outside circumstances; it can also be used to teach new information and give students multiple ways to connect their learning to prior knowledge or a new experience. Furthermore, AR can be used to teach academic vocabulary to students in a way that will not only affect them for the immediate academic year, but also in life due to the connection between vocabulary knowledge and reading comprehension.

\section{Academic Vocabulary}

For the purposes of this study, "academic language is characteristic for academic contexts, cognitively more demanding and composed of more complex lexical and grammatical structure," which will allow students to participate more easily in their general academic careers (Schuth, Köhne, \& Weinert, 2017, pp. 157-158). The vocabulary words referenced in this study allow students to participate more easily in their academic work and differ from the vocabulary used in their everyday spoken language. Furthermore, academic language can be defined as "specialized language, both oral and written, of academic settings that facilitated communication and thinking about disciplinary content" (Nagy \& Townsend, 2012, p. 92). These vocabulary words frequently appear in classroom questioning, essay prompts, assessments, texts, and other activities in which students engage throughout all aspects of their academic careers.

\section{Vocabulary Effect on Academics}

Multiple studies have shown that a student's vocabulary knowledge affects them in various academic ways; "measures of vocabulary knowledge predict literacy, academic, and cognitive outcomes throughout one's lifespan and mastery of core vocabulary is necessary for developing adult reading comprehension skills" (Kapelner, Soterwood, Nessaiver, \& Adlof, 2018, p. 13). Not only will the vocabulary a student learns while in school benefit them in their grade school career, but it will also help them throughout their entire adult life. Additionally, "vocabulary knowledge is one of the most important predictors of reading comprehension" (Quinn, Wagner, Petscher, \& Lopez, 2014, p. 160). This continues to support the idea that when students can understand the vocabulary in a text, they can more easily comprehend what they are reading, which can lead to greater success in the classroom. When students can understand what they are reading or what they are asked to do, their general confidence and success rate increases just by understanding their task. 


\section{Vocabulary Acquisition \& Retention}

Vocabulary is learned through a myriad of ways. A student can be taught words through direct instruction, or they can learn words organically through context. While "the meanings of some words are taught directly, inferring meanings of words from context appears to be an important component of vocabulary development" (Quinn, Wagner, Petscher, \& Lopez, 2014, p. 159). Therefore, using an AR approach to teaching vocabulary not only allows for direct instruction of new information, but also allows for students to infer vocabulary word meanings through context by making their own connections of their new definition to a place in their AR world. Through AR, students will see and hear the words used in context and be able to anchor that new information in a way that suits their thinking. Theoretically speaking, the more students are engaged, anchoring, and making connections with vocabulary words, the longer students will be able to acquire and retain the new information, and then use these words correctly in academic settings. Thus, the retention of vocabulary will improve reading comprehension and general academic performance.

\section{Multimedia Learning Theory}

Each student learns differently. Information needs to be presented in multiple ways to reach the needs of individual students. The Cognitive Theory of Multimedia Learning (CTML) states that students learn more deeply from words and pictures than from just words alone (Mayer, 2014). This has been proven to be a valued theory for educators. Even without using an AR approach, it is crucial for educators to present new information to students in multiple ways. For example, while using the traditional flashcard approach to teaching vocabulary, it is beneficial for students to have a written definition, a visual image, and to hear the definition out loud. In this way, students are receiving the information in multiple ways and educators are able to reach all types of learners. However, using an AR approach heightens the idea of the CTML. In this way, students are not only exposed to a written, visual, and auditory message, they are also able to anchor their learning to a game scenario, prior knowledge, a 3D environment, or a new visual location/experience.

\section{Augmented Reality}

Augmented reality allows for new learning and anchor points that would not be possible otherwise while bringing a sense of gamification to the learning setting further increasing student engagement and overall learning motivation. 21st century students thrive on the instant gratification and feedback a game-like setting brings. The term AR can be "applied to any technology that blends real and virtual information in a meaningful way... that is, the notion of AR is not limited to any type of technology" (Wu, Lee, Chang, \& Liang, 2013, p. 42). Since the term is applicable to any technology blending in the real and virtual worlds, AR can be utilized with many tools in many ways, thus appealing to diverse students and satisfying different learning styles. 
Through a learning setting that is gamified, researchers have found "that the AR approach increases engagement in the learning process" (Ibrahim et al., 2018, p. 2868). Increased engagement in learning beneficial for any teacher and any student across any grade level. When students are invested in their learning, they have an easier time learning new information. Furthermore, "games activate prior knowledge and then scaffold learning and provide instant feedback; games are typically situated, meaning learning occurs in a particular context and that knowledge can later be transferred to real-life;" through games, students will be able to learning through personal experience, problem solving, and trial and error (Acquah \& Katz, 2020, p. 2). Using a gamified setting allows for multiple benefits for students. Today's students are already comfortable with opening a new game and just playing. This way, they are learning through trial and error, discussing games socially, using what they already know, and not being afraid to fail. Since students are already comfortable in the game-like setting, they are not afraid to fail because they know they can just try again without consequences.

\section{Virtual Field Trips}

In general, students love field trips and getting out of the classroom. While there are plenty of great resources and locations available to take students to for physical field trips, this is not always possible due to finances, time, or other reasons. However, it is easier than imagined to take students on virtual field trips without ever leaving the classroom using the technology students are already walking around with in their pockets. Virtual field trips "appeal to the senses while developing new concepts and vocabulary" (Blachowicz \& Obrochta, 2005, p. 262). Students can not only learn new concepts from a virtual field trip, they can also learn the new concepts in the best possible context. Through this method of teaching vocabulary, virtual field trips give students something to anchor their vocabulary learning to, which will ultimately make it easier for them to retain this information for recall later in their academic careers. Furthermore, using AR for a virtual field trip allows an educator to "present the information onto the real environment thereby creating a stronger connection between the digital content and the real environment" (Santos, et al., 2016, p. 2). Through this method, students are even able to travel to outer space and the past and learn about those times and places without ever having to leave their classroom.

\section{Research Gap}

Augmented reality is a tool that is infiltrating training courses in our society and making its way into the classroom setting. The relationship between AR and academic vocabulary acquisition and retention in high school students has not yet been clarified. Therefore, the purpose of study was to determine the relationship between using the AR teaching method and student acquisition and retention. 


\section{Research Questions}

For the purpose of this study, there are two research questions. The first question (How does augmented reality affect a learner's vocabulary acquisition and retention?) examines whether there is an impact on using augmented reality when teaching vocabulary. The second question (What differences exist between traditional flashcard-based acquisition and retention and AR-based approaches?) explores the differences between a more traditional teaching method compared to the augmented reality method of teaching. Both questions will aid in determining whether the use of augmented reality has any impact on a learner's ability to acquire and retain new information.

\section{Methods}

\section{Population}

Participant eligibility for this study was contingent upon their enrollment in the English 9, English 10, and English 11 Honors and Academic level classes for the 2020 - 2021 school year. Participants ranged in age from 14 - 18. Participants were from varying cultural backgrounds, varying socioeconomic backgrounds, and varying levels of academics.

\section{Instruments}

All participants participated in four separate vocabulary units by taking a pre-test and post-test vocabulary assessment at the beginning and end of each respective vocabulary unit (see Appendix A). The instrument assessed the participants' performance in order to measure the impact of traditional teaching methods in comparison to AR teaching methods when teaching new vocabulary. On the assessments, respective vocabulary lists were split, having 5 words assessed on matching definitions and 5 words where students had to use the word correctly in an original sentence. The researcher designed the assessments this way to look at participants ability to recall information in the matching section and their ability to apply their new learning in creating their own, original sentences.

\section{Procedures}

The researcher followed the procedure process as listed in the Procedure Flow Chart (see Appendix B). The participants learned new vocabulary words throughout four separate vocabulary units (see Appendix C), and were then assessed before and after each unit using the same respective assessment. Each unit consisted of 10 vocabulary words either from texts that students found difficult or SAT preparatory lists gathered by the researcher. These words were are used in general academic texts that participants interact with, but may not know the definition. Traditional Teaching Methods of delivering vocabulary (see Appendix D) was used for vocabulary Unit 1 and Unit 3. AR Teaching Methods of delivering vocabulary through Nearpod, utilizing the virtual field trip option 
(see Appendix E) was used for Unit 2 and Unit 4. Both methods of vocabulary instruction were delivered during the participant's regularly scheduled English class for the 2020 2021 school year, which was a 48-minute class period that met twice a week based on a hybrid, A/B day schedule. This schedule was created to accommodate COVID-19 safety restrictions. Participant responses on pre- and post- unit assessments were coded and stored in a Google Sheet to track the impacts of each method.

\section{Reflection}

After the completion of all four units and respective assessments, participants had the opportunity to debrief the process with the researcher and complete a Google Form questionnaire regarding their preferences on teaching methods from vocabulary instruction (see Appendix F). The questionnaire examined which type of teaching method participants preferred and what specific parts were the most beneficial or non-beneficial to participants. It also allowed participants to delve into the positives and negatives of each type of instruction. Participants also determined which type of learning they would like to receive in the moving forward and what helped them arrive at their decisions. Results of the questionnaire can aid in future educational choices made for participants.

\section{Results}

The researcher sought to answer, How does augmented reality affect a learner's vocabulary acquisition and retention? and What differences exist between traditional flashcard based acquisition and retention and AR-based approaches? These questions were addressed by comparing the Augmented Reality and Traditional Method populations' results. Descriptive data summarizing these results are displayed in Table 1.

Table 1. Augmented Reality vs. Traditional scores

\begin{tabular}{lccc}
\hline Measure & $\underline{\underline{N}}$ & $\underline{\text { Mean }}$ & $\underline{\text { SF }}$ \\
\hline Augmented Reality & 29 & 2 & 1.55 \\
Traditional Method & 29 & 0.72 & 1.61 \\
\hline
\end{tabular}

An independent samples $t$-test was employed to determine the existence of a statistically significant difference between the Augmented Reality and Traditional Method scores. The independent samples $t$-test indicated a $p$ value of 0.01 . This value is below the $p=$ 0.05 threshold indicating the null hypothesis was rejected. The results of the independent-sample $t$-test indicated that the mean scores for Augmented Reality and Traditional Method were significantly different, with the Augmented Reality population reporting a higher satisfaction in the quality of their learning than the Traditional Method population. Table 2 presents the results of this independent samples $t$-test. 
Table 2. Independent-Sample t-test Comparing Augmented Reality and Traditional Method Scores

\begin{tabular}{llccc}
\hline & $\underline{\mathrm{df}}$ & $\underline{\mathrm{MD}}$ & $\underline{\mathrm{t}}$ & $\underline{\mathrm{p}}$ \\
Scores & 28 & 1.28 & -3.01 & 0.01 \\
\hline
\end{tabular}

In their reflection through the post-study questionnaire, as a whole, participants claimed that while the traditional unit felt more normal to them and they liked being able to see the word and definition on the screen, the main complaints were that it was boring and much harder for them to focus during this method of teaching because there were not any visuals to hold their attention. Their reflections connect well with the results of the t-test showing that the AR teaching method was engaging, resulting in higher scores. If the AR method was not as engaging or harder to focus for students, the difference in post-assessment scores my have been more reflective of the traditional method.

Additionally, $75.9 \%$ of participants claimed it was easier to learn their new vocabulary words from the AR unit as compared to the traditional unit, and if this type of teaching were to continue, $93.1 \%$ of participants in this study would like to keep AR incorporated in some way into their learning, thus proving that "AR environments could increase participants' motivation and interest" (Wu, Lee, Chang, \& Liang, 2013, p. 46). Options were to have full AR or a mix of AR and traditional methods. $65.5 \%$ of the $93.1 \%$ wanted a mixture of $A R$ and traditional solely because they wanted a paper copy of the words and definitions to accompany their AR world.

While participants were more interested in the AR option, their chief complaints about the AR method were that they couldn't see the word and definition and if looking at the AR screen too long, it would start to hurt their eyes. A 5 - 10 minute viewing warning for eye strain is listed on the headset themselves, so that was known to be a potential drawback from the beginning. Even with the drawback of their eyes hurting, participants reported in their post-study questionnaire that the units using the AR headsets were in general more fun for them to participate in, further supporting Ibrahim, et al.'s claim that "another benefit of AR is that it brings an element of gamification to the learning task" (2018, p. 2868). When students are having fun and engaged in what they are learning, the learning becomes more natural and easier, which was clearly shown in their post-assessment data.

\section{Discussion and Conclusion}

While participating in this study, participants definitely showed a difference in pre- and post-assessment scores between the traditional and AR units of vocabulary. As shown in the Results section above, in the traditional unit, participants on average did not show even a whole point difference between their pre- and post-assessment scores.

On the other hand, in the AR unit, participants showed a solid two-point improvement on average between their pre- and post-assessment scores. In the same post-study questionnaire, many participants said they liked the AR method of teaching because 
there were visuals, which gave them something to connect to and held their attention. This supports Santos, et al.'s observation that "visualizing the information in context-rich environments using AR can aid participants in creating meaningful associations between the content and the real environment" $(2016$, p. 6). Furthermore, by being exposed to the new vocabulary words in context through their AR world, participants' learning almost occurred through first-hand experience in a natural way (Quinn, Wagner, Petscher, \& Lopez, 2014). Participants were able to come to each conclusion on their own and even continued to make connections in their post-assessment by recalling very specific pieces of the AR world into their sentence examples.

Furthermore, after completing Units 1 and 2 of the study, there were some definitive qualitative differences between the two units noticed while participants completed their post-assessments. When completing the traditional method post-assessment, there was still a look of confusion and a lack of confidence with the vocabulary words. Participants had a hard time using words correctly in their example sentence portion of their post-assessment. However, while completing the AR post-assessment, there was more of a general confidence. Participants were having a lot of the "tip of the tongue" moments where they were recalling meaning or parts of a definition but might not have been able to get all of the information out, and participants were very specifically recalling images or parts of the AR world in their example sentences. Recalling the specifics of the AR world in their examples shows how students were able to make real, lasting connections between the vocabulary word, definition, and their AR world they were learning their new information through.

In addition to the positive results of this study, the incorporation of the AR world had many supplementary positive effects on students in the classroom. Students were able to stay motivated and engaged in what they were learning because their typical distractions were diminished. This was supported through using digital games (AR) in the classroom to enhance student motivation, which in turn, boosts the outcomes of their learning (Acquah \& Katz, 2020). Students were able to use their cell phones, which are usually a substantial distraction to students, as the educational tool used to immerse students into their AR world, which turned their distractor into their engagement tool. By using their phones as their tool and lessening their distractions, it made it easier for students to engage in what they were learning. Furthermore, any type of classroom or peer pressure distractions were also removed because of the VR headsets students were using, which blocked everything except their AR world out of view. While in their AR worlds, students were also able to make their own authentic connections and examples with the vocabulary definitions instead of being given an example for them to remember.

\section{Limitations}

There were some challenges with the execution of this study. Due to implementing this study during the COVID-19 pandemic, there were plenty of outside factors working against being able to successfully complete the study as initially designed. As the Procedure Flow Chart shows, there were to be four complete vocabulary units; two 
traditional method units and two AR method units. It was designed this way in order to be able to see if there was a pattern in participants' performance in the study. However, the second unit of AR vocabulary (Unit 4) was attempted twice. First, it was taught as originally planned, but there was a school closure at the time of the week interval for the post-testing process to take place. Any data collected from that attempt was removed from the study. Unit four was then redesigned completely, taught, and when the week interval of time passed, there was a second school closure. However, there were some successes in this study alongside the challenges. Participants enjoyed using the AR headsets and scored better on their post-assessment for that unit. Through the questionnaire, they clearly showed they would want to still incorporate the AR headsets in the classroom in some capacity. Not only was this study successful in showing the impact the AR headsets made while teaching, but also give another tool participants would like to see incorporated into their learning.

As previously discussed, due to school closures constricting the study's timeframe, the study was not completed as originally designed. Future researchers could carry out additional traditional and AR vocabulary units to determine whether or not there is a true pattern in participants' performance of learning new vocabulary through an AR approach as compared to a traditional approach. AR has the potential to open a whole new world to learners at every level of education through vocabulary, writing, field trips, "hands on" experiences, and more through any content area. 


\section{References}

Acquah, E. O., \& Katz, H. T. (2020). Digital game-based L2 learning outcomes for primary through high-school participants: A systematic literature review. Computers \& Education, 143(1), 103667. doi: 10.1016/j.compedu.2019.103667

Blachowicz, C. L. Z., \& Obrochta, C. (2005). Vocabulary visits: Virtual field trips for content vocabulary development. The Reading Teacher, 59(3), 262-268. doi: $10.1598 /$ rt.59.3

Ibrahim, A., Huynh, B., Downey, J., Hollerer, T., Chun, D., \& Odonovan, J. (2018). ARbis pictus: A study of vocabulary learning with augmented reality. IEEE Transactions on Visualization and Computer Graphics, 24(11), 2867-2874.

doi: 10.1109/tvcg.2018.2868568

Kapelner, A., Soterwood, J., Nessaiver, S., \& Adlof, S. (2018). Predicting contextual informativeness for vocabulary learning. IEEE Transactions on Learning Technologies, 11(1), 13-26. doi: 10.1109/ttt.2018.2789900

Mayer, R. (2014). Cognitive theory of multimedia learning. In R. Mayer (Ed.), The Cambridge Handbook of Multimedia Learning (pp. 43-71). Cambridge: Cambridge University Press. doi:10.1017/CBO9781139547369.005

Nagy, W., \& Townsend, D. (2012). Words as tools: Learning academic vocabulary as language acquisition. Reading Research Quarterly, 47(1), 91-108.

doi: 10.1002/rrq.011

Quinn, J. M., Wagner, R. K., Petscher, Y., \& Lopez, D. (2014). Developmental relations between vocabulary knowledge and reading comprehension: A latent change score modeling study. Child Development, 86(1), 159-175. doi: 10.1111/cdev.12292

Santos, M. E. C. et al (2016). Augmented reality as multimedia: The case for situated vocabulary learning. Research and Practice in Technology Enhanced Learning, 11(4). doi: 10.1186/s41039-016-0028-2

Schuth, E., Köhne, J., \& Weinert, S. (2017). The influence of academic vocabulary knowledge on school performance. Learning and Instruction, 49(1), 157-165. doi: 10.1016/j.learninstruc.2017.01.005

Wu, H.-K., Lee, S. W.-Y., Chang, H.-Y., \& Liang, J.-C. (2013). Current status, opportunities and challenges of augmented reality in education. Computers \& Education, 62(1), 41-49. doi: 10.1016/j.compedu.2012.10.024 


\section{Appendix A - Assessments}

Participants will be assessed at the end of the week the vocabulary words are taught in their respective methods. Participants will be tested using paper/pencil methods for all testing in order to prevent forms of digital cheating, i.e. using the define tool through a Google Doc. Each assessment will ask participants to define half of the words (through matching) and use the other half of the words correctly in a sentence. They will be instructed that something along the lines of " is one of my vocabulary words" is not an acceptable response. Participants will be able to change word endings to properly use them in their sentences. For example, a student may change "usurp" to "usurped" to make it fit their sentence correctly.

\begin{tabular}{|c|c|c|c|}
\hline Unit 1 & Unit 2 & Unit 3 & Unit 4 \\
\hline $\begin{array}{l}\text { Definition: } \\
\text { candor } \\
\text { enthrall } \\
\text { flourish } \\
\text { loquacious } \\
\text { supercilious }\end{array}$ & $\begin{array}{l}\text { Definition: } \\
\text { formidable } \\
\text { insidious } \\
\text { laconic } \\
\text { lucid } \\
\text { paradigm }\end{array}$ & $\begin{array}{l}\text { Definition: } \\
\qquad \text { boisterous } \\
\text { exult } \\
\text { decorum } \\
\text { impertinent } \\
\text { voracious }\end{array}$ & $\begin{array}{l}\text { Definition: } \\
\text { ambivalent } \\
\text { conviction } \\
\text { disdain } \\
\text { nuance } \\
\text { petulant }\end{array}$ \\
\hline $\begin{array}{l}\text { Usage: } \\
\text { commemorate } \\
\text { divulge } \\
\text { facetious } \\
\text { quandary } \\
\text { undulate }\end{array}$ & $\begin{array}{l}\text { Usage: } \\
\text { accentuate } \\
\text { copious } \\
\text { eclectic } \\
\text { pretentious } \\
\text { usurp }\end{array}$ & $\begin{array}{l}\text { Usage: } \\
\text { frugal } \\
\text { imperative } \\
\text { incognito } \\
\text { omnipotent } \\
\text { recede }\end{array}$ & $\begin{array}{l}\text { Usage: } \\
\text { benevolent } \\
\text { enumerate } \\
\text { insatiable } \\
\text { scrupulous } \\
\text { ubiquitous }\end{array}$ \\
\hline
\end{tabular}




\section{Vocabulary Unit 1 Quiz}

Name: Date:

Class PD:

Score:

\section{Vocabulary Unit 1 Quiz}

Directions: Section 1 - Match the woro with the correct definition. Please clearly write the capital letter of your choice on the line next to the word. Illegible writing will be marked incorrect.

Word

Definition

1. Candor

2. Enthrall

3. Flourish

4. Loquacious

5. Supercilious
A. to hold the attention of (someone) by being very exciting, interesting, or beautiful

8. liking to talk and talking smoothly and easily

C. having or showing the proud and unpleasant attizuce of people who think that they are better or more imporiant than other people

D. the quality of being open, sincere, and honest

E. to be very successful : to do very well ; to grow well : to be healthy

Directions: Section 2 - Use the given word correcily in an original sentence. You may NOT use " is one of my vocabulary words" as an acceptable response. You may, however, change the word ending to make it work with the tense of your sentence. For example, you may change "usurp" to "usurped" to make it fit your sentence correctly. Flip over to the back if you need more room. Remember punctuation \& capitalization!

1. Commemorate:

2. Divulge:

3. Facetious:

4. Quandary:

5. Undulate: 


\section{Vocabulary Unit 2 Quiz}

Name: Date:

Class PD: Score: $/ 20$

\section{Vocabulary Unit 2 Quiz}

Directions: Section 1 - Match the word with the correct definition. Please clearly write the capital letter of your choice on the line nexi to the word. Illegible svriting will be marked incorrect.

Word

1. Formidable

2. Insidious

3. Laconic

4. Lucid

5. Paradigm
Definition

A. a model or pattern for some:hing that may be copied

B. very clear and easy to understand

C. using few words in speech or writing

D. causing harm in a way ihat is gradual or not easily noticed

E. very powerful or strong : deserving serious attention and respect

Directions: Section 2 - Use the given word correcily in an original sentence. You may NOT use " is one of my vocabulary words" as an acceptable response. You may, however, change the word ending to make it work with the tense of your sentence. For example, you may change "usurp" to "usurped" to make it it your sentence correctly. Flip over to the back if you need more room. Remember punciuation \& capitalization!

1. Accentuate:

2. Copious:

3. Eclectic:

4. Pretentious:

5. Usurp: 


\section{Vocabulary Unit 3 Quiz}

Name: Date:

Class PD: Score: $/ 20$

\section{Vocabulary Unit 3 Quiz}

Directions: Section 1 - Match the word with the correct definition. Please clearly write the capital letter of your choice on the line next to the word. Illegible writing will be marked incorrect.

\section{Word}

1. Boisterous

2. Exult

3. Decorum

4. Impertinent

5. Voracious
Definition

A. to say (something) in a very excited and happy way

B. correct or proper behavior thai shows respec: and good manners

C. having or showing a tendency to eat very large amounts of food

D. very noisy and active in a lively way

E. rude and showing a lack of respect

Directions: Section 2 - Use the given word correctly in an original sentence. You may NOT use " one of my vocabulary words" as an acceptable response. You may, however, change the word ending to make it work with the tense of your sentence. For example, you may change "usurp" to "usurped" to make it int your sentence correctly. Flip over to the back if you need more room. Remember punciuation \& capitalization!

1. Frugal:

2. Imperative:

3. Incognito:

4. Omnipotent:

5. Recede: 


\section{Vocabulary Unit 4 Quiz}

Name: Date:

Class PD: Score: $/ 20$

\section{Vocabulary Unit 4 Quiz}

Directions: Section 1 - Match the word with the correct definition. Please clearly write the capital letter of your choice on the line next to the word. Illegible writing will be marked incorrect.

Word

1. Ambivalent

2. Conviction

3. Disdain

4. Nuance

5. Petulant
Definition

A. the feeling of being sure that what you believe or say is irue

B. a very small difference in color, tone, meaning, etc.

C. having or showing the attitude of people who become angry and annoyed when they do not get what they want

D. a feeling of sirong dislike or disapproval of someone or something you think coes not deserve respect

E. having or showing very different feelings (such as love and hate) about someone or someining at the same time

Directions: Section 2 - Use the given word correcily in an original sentence. You may NOT use "is one of my vocabulary words" as an acceptable response. You may, however, change the word ending to make it work with the tense of your sentence. For example, you may change "usurp" :o "usurped" to make it fit your sentence correctly. Flip over to the back if you need more room. Remember punctuation \& capitalization!

1. Benevolent:

2. Enumeraie:

3. Insaniable:

4. Scrupulous:

5. Ubiquitous: 


\section{Appendix B - Procedure Flow Chart}

Pre-test on unit 1 vocabulary words

Unit 1: Traditional teaching of vocabulary words to students

Test students in 1 week from teaching (Unit 1 words)

Pre-test on unit 2 vocabulary words

Unit 2: AR vocabulary field trip method of teaching vocabulary to students

Test students in 1 week from teaching (Unit 2 words)

Pre-test on unit 3 vocabulary words

Unit 3: Traditional teaching of vocabulary words to students

Test students in 1 week from teaching (Unit 3 words)

Pre-test on unit 4 vocabulary words

Unit 4: AR vocabulary field trip method of teaching vocabulary to students

Test students in 1 week from teaching (Unit 4 words) 


\section{Appendix C - Unit Word Lists}

These words were chosen for this study based off of the previous school year student struggles. There are no repeated words that were specifically studied in any of their English classes. These are words participants will come across in their academic paths through high school and beyond. Definitions for each word from Merriam-Webster's Learner's Dictionary

\begin{tabular}{|l|l|l|l|}
\hline \multicolumn{1}{|c|}{ Unit 1 } & \multicolumn{1}{|c|}{ Unit 2 } & \multicolumn{1}{c|}{ Unit 3 } & \multicolumn{1}{c|}{ Unit 4 } \\
\hline candor & accentuate & boisterous & ambivalent \\
commemorate & copious & exult & benevolent \\
divulge & eclectic & frugal & conviction \\
enthrall & formidable & decorum & disdain \\
facetious & insidious & imperative & enumerate \\
flourish & laconic & impertinent & insatiable \\
loquacious & lucid & incognito & nuance \\
quandary & paradigm & omnipotent & petulant \\
supercilious & pretentious & recede & scrupulous \\
undulate & usurp & voracious & ubiquitous \\
& & & \\
\hline
\end{tabular}




\section{Appendix D - Traditional Teaching Method}

For the purpose of this study, "Traditional Teaching Method" will be defined as vocabulary words given as word, part of speech, definition, and example(s) through Google Slides.

\section{Unit 1 Vocab.}

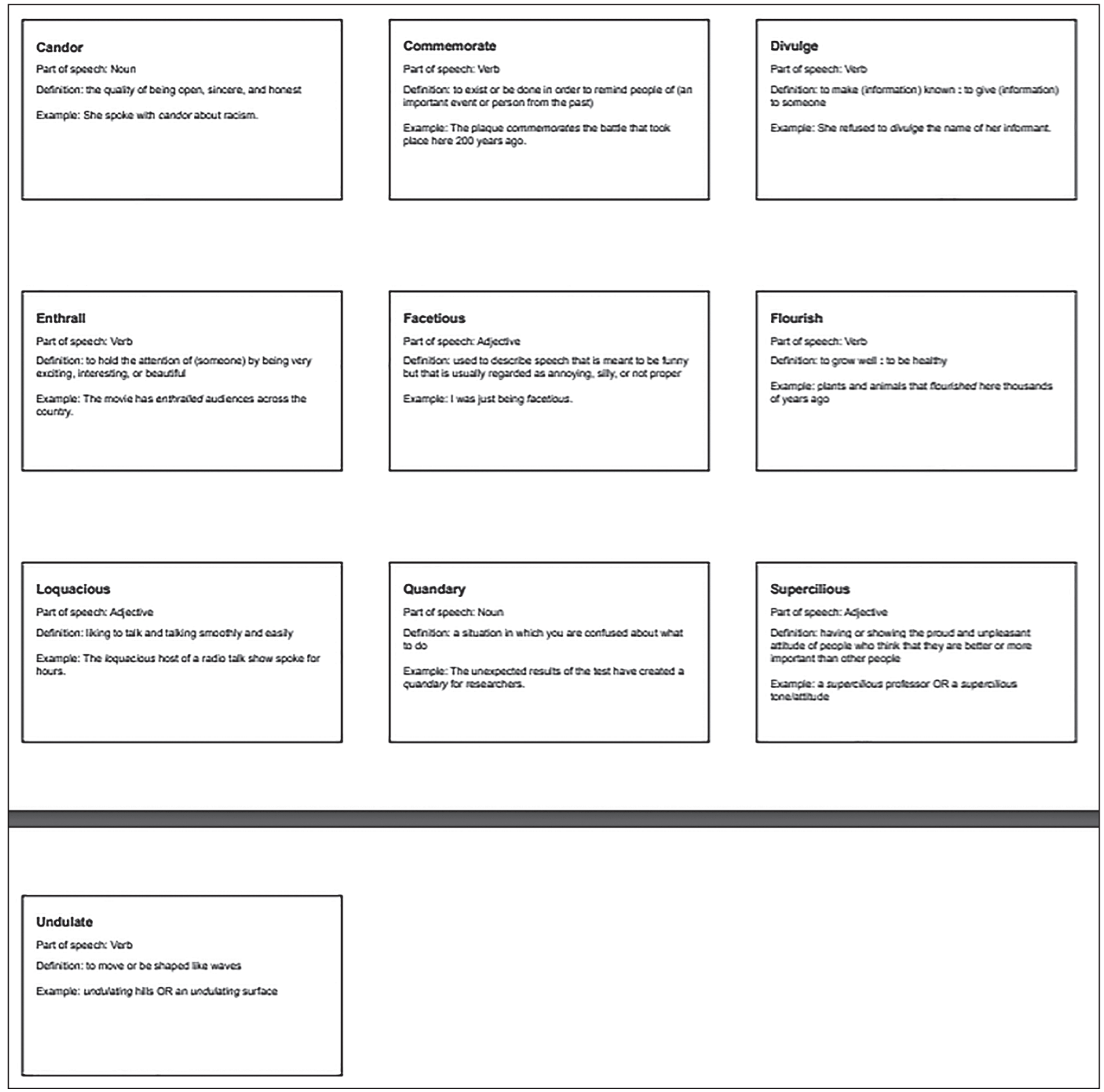


Unit 3 Vocab.

Boisterous

Part of specect Aesoctive

Defriton: very noisy and active in a livily way,

Exampic: Alarge and basterous crowd abondod the conoert.

Decorum

Past of epeecex Noun

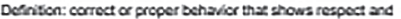
good manners

Example: Court onconum requires sat all partes adsess the joge as Your Hisnoc"

Part of spsecor A Arero

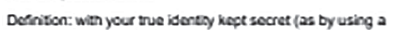

oflecot name or a daguee)

Example: He troncta
Exult

Pat cl speect Veto

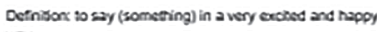

way

Example: She crams over her atusers' test ecores

Imperative

Part cl specect Adjective

Defntron very imcorts:

Erample: it is imperaste that the putic be informod nowe

nese congers.
Frugal

Part de speect iljective

Defrison carefl zoout sponeng money of using rings

unen you 60 net nosd to

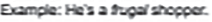

Impertinent

Part d epeect: nejective

Defrison nude and showing a look of respect

Bample: She ziked atsu impornert Questons

\section{Omnipotent}

Part ot spescri Adjective

Defnron having complete or unlimbed powor

Example omipctent goses or an omnipotent wilersatse

\section{Recede}

Part of sponct: vers

Defrison to move sway growaly

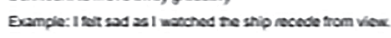

Voracious

Pan of spescox Aquective

Defriton: having or a howing a sendoncy wo exs very large

amouns of 1000

Example: He has a varaious appesene. 


\section{Appendix E - AR Teaching Method}

For the purpose of this study, "AR Teaching Method" will be defined as virtual teaching vocabulary words through the use of Nearpod's virtual field trips. This will incorporate words, definitions, parts of speech, visuals, and words used in context when teaching.

Unit 2 - Participants will have the following script read aloud to them while they look around the AR version of "New York Times Square at dusk" powered by 360 Cities through Nearpod.

Script:

Accentuate is a verb that means to make (something) more noticeable. Look around at the signs and buildings. What stands out to you that accentuates this part of New York? Copious is an adjective that means very large in amount or number. Look at the copious amount of people standing in Times Square. Eclectic is an adjective that means including things taken from many different sources. Look for the eclectic mix of advertisements and Broadway Show posters hanging on the buildings. Formidable is an adjective that means very powerful or strong: deserving serious attention and respect. Again, look at the advertisements and show posters. What stands out to you as being formidable? Insidious is an adjective that means causing harm in a way that is gradual or not easily noticed. Look around at the size of the crowd. Is there anything that could be considered insidious in any way? Laconic is an adjective that means using few words in speech or writing. Looking at this shot of Times Square as a whole, how could you describe it in a laconic manner? Lucid is an adjective that means very clear and easy to understand. What stands out to you as being lucid in this shot of Times Square? Paradigm is a noun that means a model or pattern for something that may be copied. Look at all the buildings surrounding Times Square, do any of them look like they were a paradigm for the rest of the city or maybe even the other buildings? Pretentious is an adjective that means having or showing the unpleasant quality of people who want to be regarded as more impressive, successful, or important than they really are. Is there anything about this shot of Times Square that seems pretentious to you? Why? Usurp is a verb that means to take and keep (something, such as power) in a forceful or violent way and especially without the right to do so. If you could usurp any part of New York, would it be Times Square? 


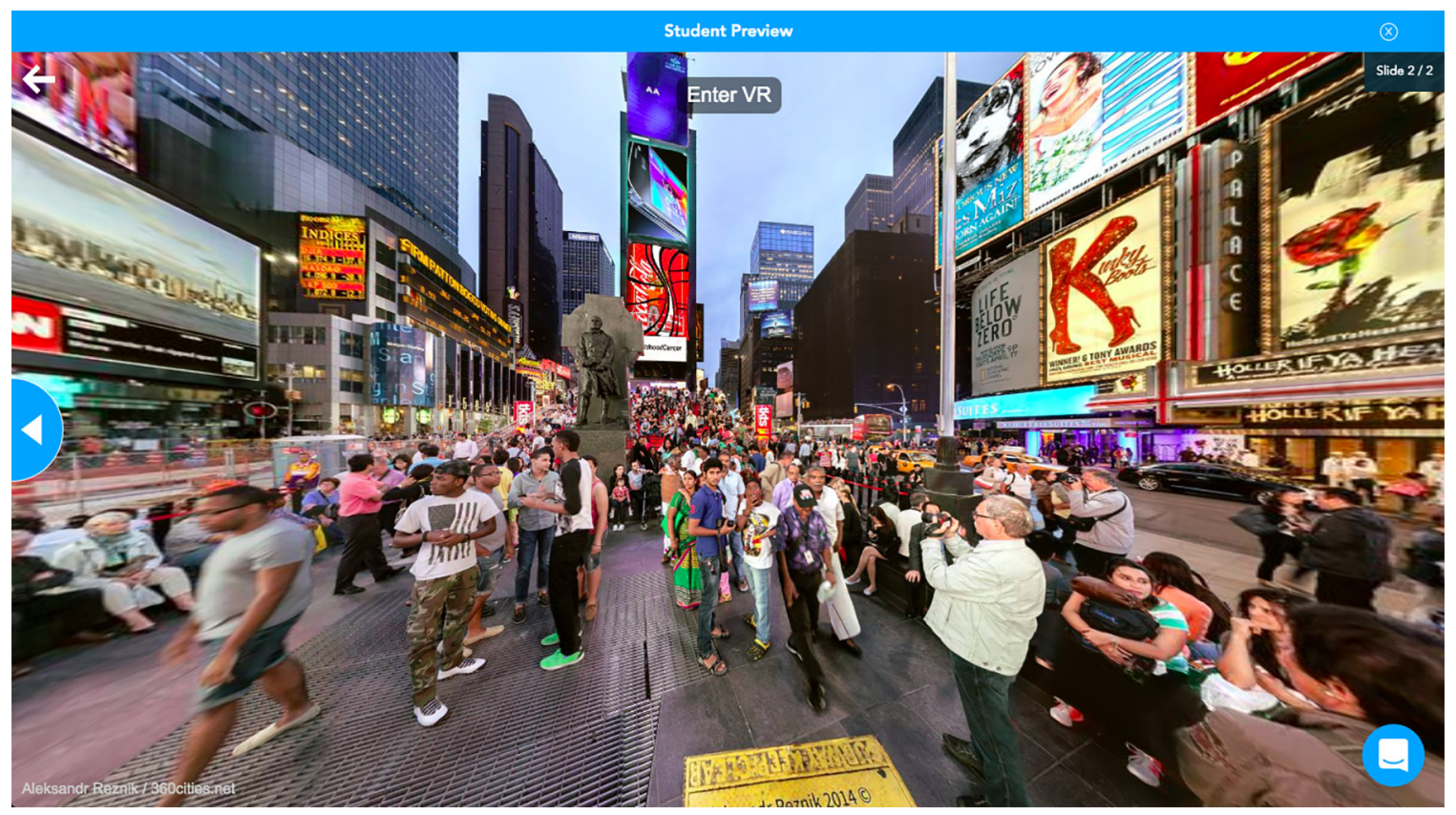

Unit 4 - Participants will have the following script read aloud to them while they look around the AR version of "Super Bowl LIV in Downtown Miami" powered by 360 Cities through Nearpod.

Script:

Ambivalent is an adjective that means having or showing very different feelings (such as love and hate) about someone or something at the same time. Unless someone's favorite football team is in the Super Bowl, most people are ambivalent about who wins. Benevolent is an adjective that means kind and generous. Find one of the billboards or company signs around the city. Do you think any of them were benevolent donors? Conviction is a noun that means the feeling of being sure that what you believe or say is true. Find the Lay's chips sign. Their advertisement is stating with conviction that their chips are "yummy." Do you agree? Disdain is a noun that means a feeling of strong dislike or disapproval of someone or something you think does not deserve respect. Find the halftime show poster. Some people may have watched the halftime show with disdain and so may not. Enumerate is a verb that means to name (things) one after another in a list. Look around at all the various decorations and lights on the ground. Whoever was in charge of decorating the area had to enumerate the items on their list to make sure they had everything. Insatiable is an adjective that means always wanting more : not able to be satisfied. Coaches and players are insatiable about Super Bowl rings; one is never enough. Nuance is a noun that means a very small difference in color, tone, meaning, etc. Look at the palm tree decorations on the field. Can you find any nuances in their appearance? Petulant is an adjective that means having or showing the attitude of people who become angry and annoyed when they do not get what they want. The 
losing team of the Super Bowl each year leaves the field petulant and angry they are not the champions. Scrupulous is an adjective that means very careful about doing something correctly. Look at the lettering on the field. The person in charge of lettering had to pay scrupulous attention to details when painting the letters. Ubiquitous is an adjective that means seeming to be seen everywhere. Look at the purple and blue lights that are ubiquitously placed around the area.

Unit 4 AR screenshot

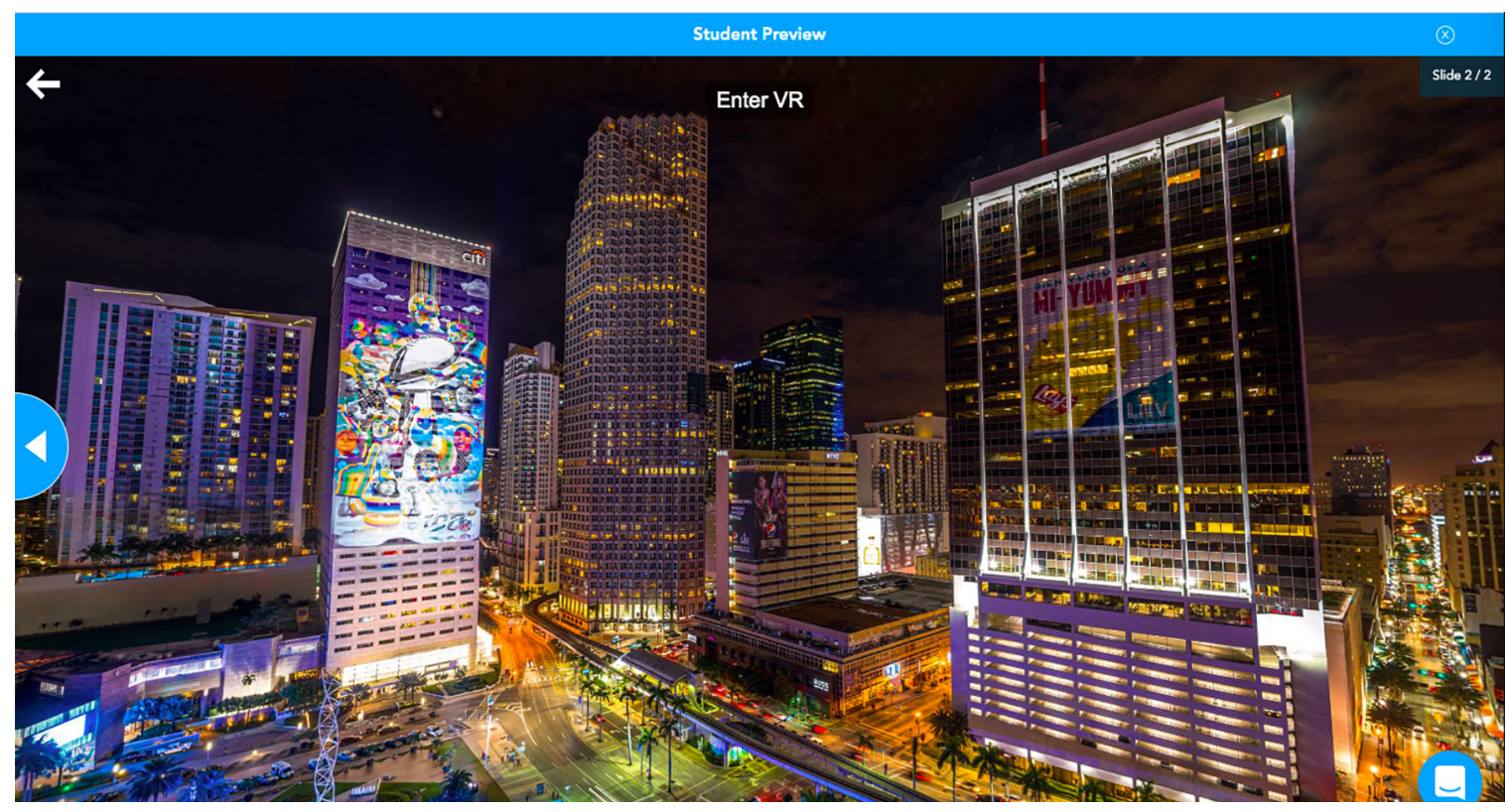




\section{Appendix F - Questionnaire}

\section{Questionnaire}

Fill out the following questionnaire openly and honestly as possible. I will be the only one who reads your responses.

* Required

Name *

Your answer

What did you like about the traditional teaching methods? *

Your answer

What did you not like about the traditional teaching methods? *

Your answer

What did you like about the AR teaching methods? *

Your answer 
Questionnaire, continued

What did you not like about the AR teaching methods? *

Your answer

Which method did you find it easier to learn from? *

Traditional

Augmented Reality (headsets)

Explain your choice from the question above. *

Your answer

If this routine of vocabulary would continue, how would you like the vocabulary delivered in class? ${ }^{\star}$

$\bigcirc$ Traditional

C AR

A mixture of traditional \& AR

Neither

\section{Submit}

